\title{
Lambda z TAU
}

National Cancer Institute

\section{Source}

National Cancer Institute. Lambda z TAU. NCI Thesaurus. Code C147481.

The first order rate constant associated with the terminal (log-linear) portion of the curve, calculated within a dosing interval. 